\title{
An Exploratory Study on COVID-19 and the Rights of Children Based on Keyword Network Analysis
}

Seoyeon Lee ( $\nabla$ sci3on@hanmail.net)

Delaware State University https://orcid.org/0000-0001-6819-6394

\section{Research Article}

Keywords: COVID-19, children's right, big data, network analysis, children

Posted Date: February 12th, 2021

DOI: https://doi.org/10.21203/rs.3.rs-156498/v1

License: (9) This work is licensed under a Creative Commons Attribution 4.0 International License. Read Full License 


\section{Abstract}

COVID-19 has become a worldwide health crisis. Around March 2020, the entire country was shut down, including schools. This resulted in significant changes in the lives of children. In this study, the researcher conducted a keyword network analysis utilizing Ucinet ver 6.716 and NetDraw ver 2.173, after gathering the data using Textom in order to examine the current status of the rights of children in a COVID-19 pandemic. The findings of this study were that the degree centrality was higher with poverty, educational institutions, parents, teachers, income support, child care, child-rearing, caring, online classes, and child welfare, etc. Therefore, it can be said that there is an urgent need for the implementation of the respect of the rights of children all over the world in this COVID-19 pandemic.

\section{Introduction}

The UN Committee on the Rights of the Children expressed concern over the impact of COVID-19 on children and made a statement demanding that the roles of the member countries include the rights of the children to survive, be protected, grow, and participate in decisions related to their rights.

Additionally, Human Rights Watch conducted a campaign, which demanded that Prime Minister Kyriakos Mitsotakis of Greece release children incarcerated in unsanitary lockup conditions in police stations or other incarceration facilities without guardians accompanying them (Human Rights Watch, 2020).

The reason many international organizations such as the UN are chiefly concerned with children's rights in light of COVID-19 is that they now face a health crisis under which their rights could be compromised. First, children are exposed to significant risks in terms of nutrition, medical care, and hygiene, which relate to their very survival. UNICEF reported that the number of children in Congo who received vaccinations decreased significantly after the onset of the COVID-19 pandemic, fearing an increase in the number of serious disease cases among the affected children (when comparing case numbers in January and February of 2019 and to January and February of 2020). Additionally, select measures are urgently needed for children with needs stemming from poverty, migration, or being refugees. ILO and UNICEF reported that, with each $1 \%$ increase of families in poverty due to COVID-19, child labor increases by $0.7 \%$, aggravating the problem of child labor.

COVID-19 caused a significant change in terms of children's learning, leisure, and play, which closely relate to their development. Professor Ikjoong Jeong of Iwha Women's University (Department of Social Welfare)in his presentation themed "the changes in the daily lives of children after COVID-19 and their happiness," reported that the level of perceived happiness among children decreased, while anxiety about the future and stress levels increased. Additionally, children face the difficulty of not having a chance to participate. Therefore, the government, local communities, and families communicate information related to COVID-19 in language that children understand and provide these children with the opportunity to participate in decision making related to their rights. 
Since the worldwide lockdown and school shutdown in March 2020, children have been required to remain at home for a very long period of time. With this requirement, the fear is that child abuse may also increase, since caregivers of children are under more stress. A number of violent cases against children have occurred, which has created a social issue. With a series of child abuse cases, the need for measures to prevent child abuse is also more urgent than ever. For this reason, the UN has advised world governments to focus greater attention on protecting children and their rights as they plan and execute measures to respond to and restore societies impacted by COVID-19 in the guideline for human rights, which was announced in April 2020. The UN also advised that supporting and protecting children in a crisis must be a priority.

As such, COVID-19 has changed society in general, including children's lives. Therefore, this research intends to examine COVID-19's impact on children's rights and examine the requirements for children's rights in a pandemic in order to protect children's rights under COVID-19. Considering the fact that COVID19 spread over a very short period of time, this research used big data to gather various types of data.

Big data is characterized by hyper-connectedness and hyper-intelligence in the era of the 4th Industrial Revolution, allowing rapid processing and analysis of a large amount of information from the Internet (Yeonseung Lee, 2017) in order to analyze complicated meanings and make inferences, which are the advantages of this new technology (Woojin Jeong, 2014). Specifically, a network analysis using keywords makes it possible to analyze the overall structure of the studies (Jonghoon Kim, Wooshik Choi, and Mira Jeong, 2017).

What are the requirements for children's rights under COVID-19?

\section{Methods}

\section{Data gathering}

In this study, the researcher used Textom, a big data analysis solution, to gather raw data, focusing on the headings and summary information for the search hits of search engines that included Naver, Daum, Baidu, Google, YouTube, Facebook, etc. The data-gathering period was one year: from August 28, 2019 to August 28, 2020. The raw data was gathered using the keywords "COVID-19 + children's rights," and the total volume of data gathered was $10.64 \mathrm{MB}$.

\section{Analysis tool}

For data gathering for and refining this study on COVID-19 and children's rights, the researcher used Textom, a big-data analysis solution developed by The IMC Co., Ltd. Additionally, to analyze the network of keywords related to children's rights, the researcher used Ucinet (version 6.716) and NetDraw (version 2.173) (Borgatti, Everett $\otimes$ Johnson, 2013).

\section{Data processing and analysis}


The raw data gathered by Textom for this study's purpose went through a data cleaning process in order to clarify keywords' meanings for this study's outcomes. As the first mining, the researcher conducted a text mining, focusing on the nouns included in the raw data gathered by Textom. The following second refinement was performed using Textom's "Edit Now" function; keywords that were irrelevant to the core keywords or not suitable for the analysis were removed. This step was followed by a frequency analysis based on the refined data after the 1 st and 2 nd data cleanings. Based on the frequency analysis results of the extracted words, 200 upper-level nodes were designated and used to prepare a $200 \times 2001$-mode matrix dataset (Borgatti et al., 2013).

\section{Results}

First, the researcher conducted a keyword analysis based on the refined data from the 1st and 2nd data cleaning. The frequency analysis results showed that the top-10 most relevant keywords for children's rights were as follows:

Table 1 The result of the frequency analysis

\begin{tabular}{|lllll|}
\hline 1. Poverty & 2. Education institution & 3. Parents & 4. Income support & 5. Teachers \\
\hline 6. Care & 7. Rearing & 8. Online learning & 9. Childcare & 10. Family \\
\hline
\end{tabular}

The frequency analysis results were that "poverty" was the most frequently used keyword, occurring 2459 times, followed by "education institution" (2396), "parents" (1936), "income support" (1353), "teachers" (1188), and "care" (1067). In addition to the top-10 keywords, a variety of other keywords were also gathered. The top-200 included playing, development retardation, emotion, rights, child abuse, learning gap, obesity, remote learning, playgrounds, growth impediment, children policy, child benefits, disaster relief, etc. As such, it was shown that COVID-19 significantly impacted children's rights, and many current issues surround children's rights. Within the issues related to children's rights, it was also shown that many changes are happening in terms of child poverty, parents, livelihood, development, emotion, nutrition, obesity, learning, playing, participation, policies, etc.

Second, the researcher used Ucinet (version 6.716) and NetDraw (version 2.173) to conduct a keyword network analysis on COVID-19 and children's rights. For this analysis, the researcher used the results of the frequency analysis of the extracted words to designate the top-200 nodes, which were then used to prepare a 200 x 2001 -mode matrix dataset.

The result of the keyword network analysis is shown in Fig. 1. The degree centrality of the keyword network analysis was "poverty" (0.032), "education institution" (0.030), "parents" (0.027), "teachers" 
(0.021), "income support" (0.018), "childcare" (0.016), "child-rearing" (0.015), "care" (0.014), "online learning" (0.011), and "child welfare" (0.011).

\section{Conclusion}

COVID-19 has significantly impacted children's rights. Since COVID-19, a significant amount of effort has been put into details related to securing children's rights worldwide.

To secure such rights for children, many international organizations, including the United Nations, are preparing and implementing reports and guidelines for children's rights. In addition, each nation continues with its efforts to secure children's rights. First, for children's survival and protection, the State of New York decided to designate a proxy guardian to assume parents' role and provide childcare services if the children of low-income families must be separated from their parents because their parents have confirmed COVID-19 cases or are hospitalized (OCFS, 2020). To provide financial relief to those affected by COVID-19, the US federal government introduced the Coronavirus Aid, Relief, and Economic Security Act in March 2020 (Coronavirus Aid, Relief, and Economic Security Act) (Federal Transit Administration, 2020; Federal Communications Commission, 2020; California Government, 2020a; Novel Coronavirus, 2020). Additionally, regarding children's mental health, the Journal of the American Academy of Child and Adolescent Psychiatry warned that social isolation due to COVID-19 might affect children's mental health (depression and anxiety), of which the effects may last for almost a decade. Marking these words, the UK and US governments now operate 24-hour online consultation and helplines to provide mental-healthrelated support (California Coronavirus Response, 2020; NYC Health, 2020, Public Health England, 2020).

World governments must also respond to children's needs in terms of education, leisure, and playing for their development. Even when school is not fully functioning, children's rights to learn must be secured. Therefore, an education system that can cover even needy populations is dearly needed. The British government provides a community-level helpline for education and childcare facilities while designating children in need and critical workers, so that people can use schools and childcare facilities even during school shut-downs (Department for Education \& Public Health England, 2020; Department for Education, 2020c).

Last, issues of child abuse, violence, sexual abuse, and exploitation of children must be addressed. US state governments now provide detailed guidelines for using video-conferences, and they have established systems to allow anonymous reporting online (Federal Bureau of Investigation News, 2020. 05. 20). Additionally, the US federal government provides a 24-hour domestic violence hotline service and a live-chat service in case the perpetrator lives with victims (Benefit.gov, 2020).

As such, efforts to protect children's rights are ongoing worldwide. However, more attention must be paid to protecting children and their rights as governments plan their response to and recovery from COVID-19; such plans must be executed to consider children's best interests. 


\section{Declaration}

The author declares no competing interest.

\section{References}

Benefit.gov (2020). Hotline support. Retrieved from https://www.benefits.gov/help/faq/

Coronavirus-resources

Borgatti, S. P., Everett, M. G., \& Johnson, J. C. (2013). Analyzing social networks. Thousand Oaks, CA: Sage Publications

California Coronavirus Response (2020). Resources for emotional support and well-

being.

California Government (2020a). Get financial help.

Department for Education (2020c). Actions for early years and childcare providers during the coronavirus outbreak.

Department for Education \& Public Health England. (2020). Coronavirus (COVID-19): Guidance for educational settings.

Federal Communications Commission (2020). Lifeline program for low-income consumers.

Federal Transit Administration (2020). Coronavirus aid, relief, and economic security(CARES) Act.

Health Central (2020). .How to Help Kids Deal With Loneliness Right Now $\square$

Human Right Watch (2020). Greece: Free Unaccompanied Migrant Children: New Campaign to Shelter Children, End Detention Amid COVID-19

ILO, Unicef (2020). COVID-19 and Child Labour: A Time of Crisis, A Time to Act.

Novel Coronavirus (2020). Information on novel coronavirus.

NYC Health (2020). Covid-19: Coping and emotional well-being.

Office of Children and Family Services (2020). Novel Coronavirus of 2019 disease (COVID-19): Guidance for children protective services staff.

Public Health England (2020). Guidance for parents and carers on supporting children and young people's mental health and wellbeing during the coronavirus (COVID-19) pandemic. 
The Alliance for Child Protection in Humanitarian Action (2020). Technical note: Protection of children during the Coronavirus pandemic (v.1).

'The 17 Child Welfare Forum held with a theme of 'The Changes in Daily Lives due to COVID-19 and the Happiness of Children' (June 6, 2020)

Yeonseung Lee (2017). A Basic Research to Use Big-Data in the Field of Toddlers Education. Toddlers Education Research, 37 (4), 585-610.

Woojin Jeong (2014). Talking about the Big Data Seoul: Cloud Books.

Jonghoon Kim, Wooshik Choi, and Mira Jeong (2017). The Research Trend and Intellectual Structure of 'Toddlers Education Research' by Keyword Network Anlaysis Toddlers Education Research, 37(3), 269288.

UN (2020). We are all in this Together: Human Rights and COVID-19 Response and Recovery.

UN (2020). "Protect our children"

\section{Figures}

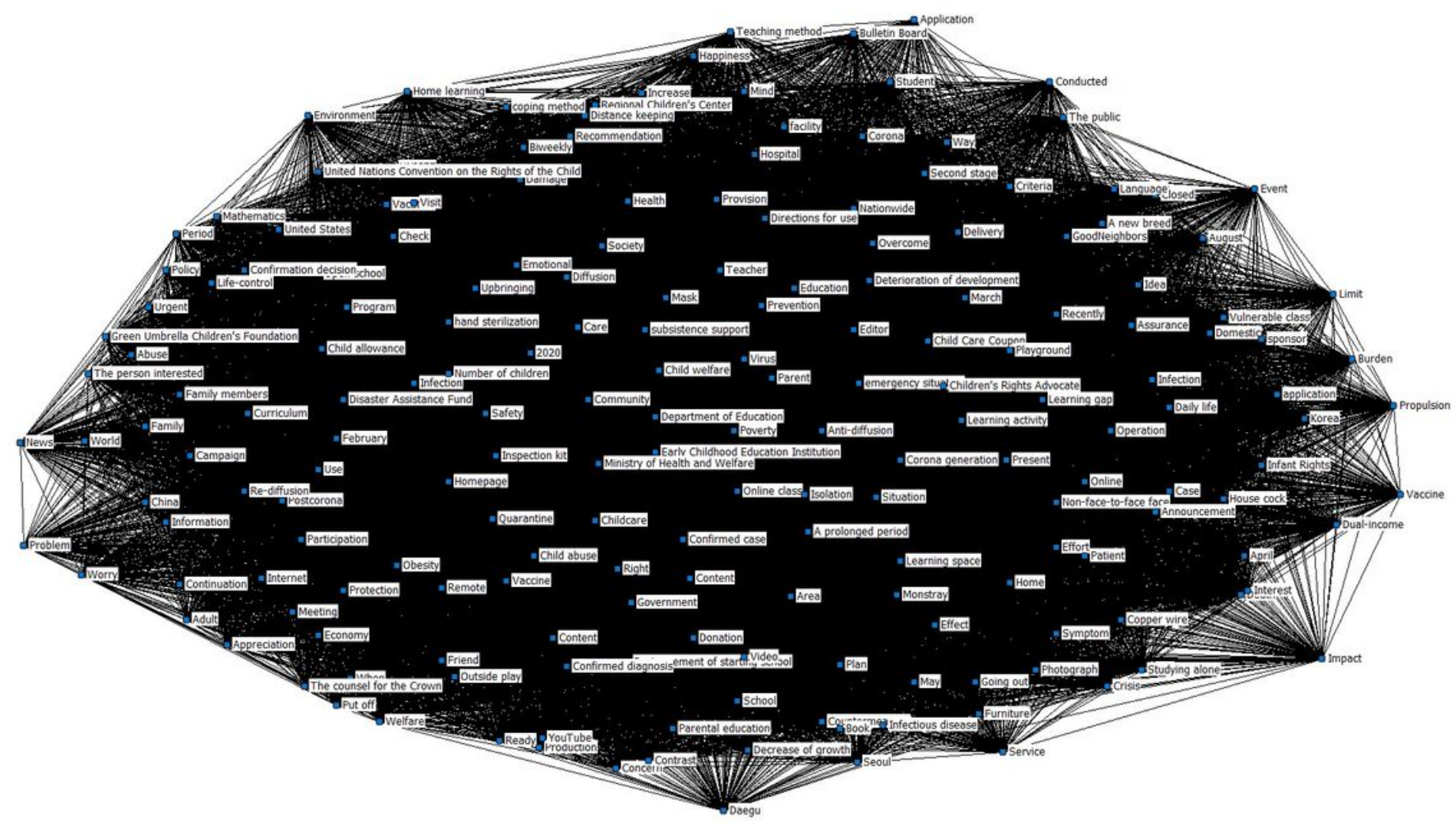

Figure 1

Keyword network analysis 